\title{
Computer analysis of the different water hammer protection systems
}

\author{
Fathy M. Radwa ${ }^{1}$, El Sayed T. ${ }^{2}$, Hamdy W. ${ }^{3}$, and Ramdan K. ${ }^{4}$
}

\begin{abstract}
:
Water hammer is defined as a pressure surge or wave caused when a fluid in motion is forced to stop or change direction suddenly. This pressure wave can cause major problems to transmission pipes..

The present study aims to investigate problems resulting from unsteady flow and then investigate the effect of using a protection device; air vessel only, surge tank only and air vessel with surge tank; to protect pipelines against water hammer. Through this work, the study is applied using Water Hammer Software Wanda V3.30.

In the present study for transient condition caused by pump failure, it is found that using the proposed an air vessel as a protection device proved to be effective for prevent column separation, using of air vessel with two surge towers will not effect the total volume of protection. Increases the diameter of the pipeline reduces the surge pressures and decrease the total volume required to protect the system. Otherwise, change of pipe material type from Glass Reinforced Plastic to steel decreases the minimum pressure but does not effect the total volume required to protect the system and change of pipe material type from Glass Reinforced Plastic to concrete decreases the minimum pressure and the total volume required to protect the system. Finally found that as the air vessel volume is reduced the number of used air vessels is increased and the negative pressure of the pipe line not affected.

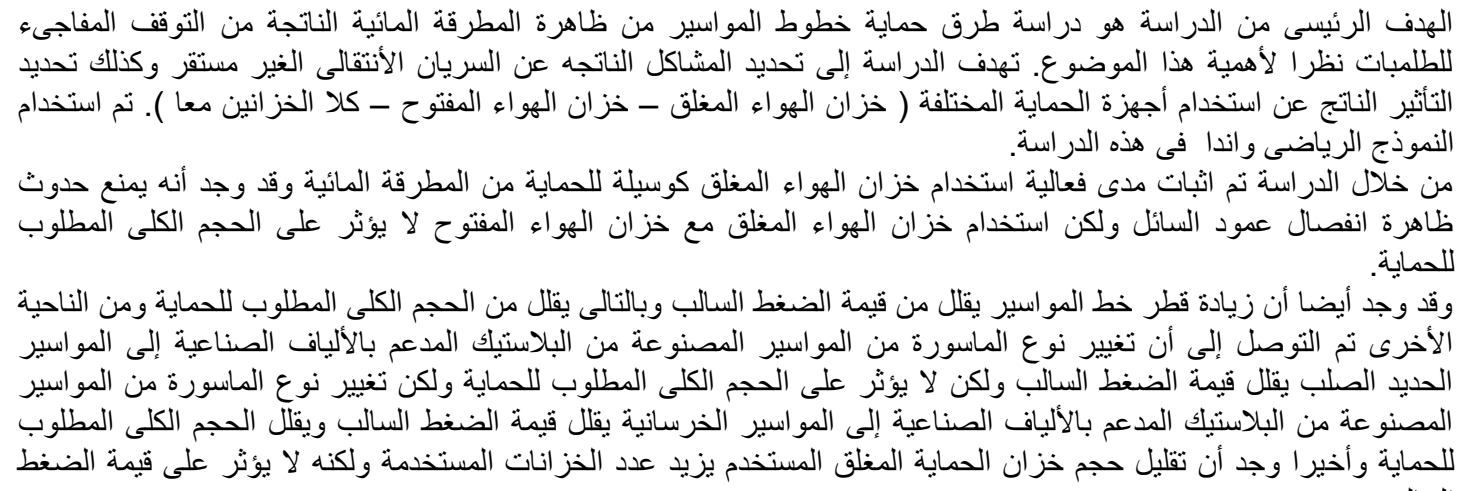

السالب.

Keywords: Water Hammer, Pipe Line, Cavitation, Air Vessel

${ }^{1}$ Assistant Researcher, Hydraulics Research Institute, National Water Research Centre, Egypt

${ }^{2}$ Assistant Prof., Mataria Faculty of Engineering, Helwan University, Egypt

${ }^{3}$ Assistant Prof., Mataria Faculty of Engineering, Helwan University, Egypt

${ }^{4}$ Director of Hydraulics Research Institute, National Water Research Centre, Egypt

\section{1- INTRODUCTION:}

In transient flow through pipeline, the common concern of the hydraulic engineers is to control the effect of pressure head in order to protect the relevant system components. The problems arising from transient flow in pipeline result from the various operating conditions such as stopping or starting-up of a pump and valve closure or valve opening from a pipeline. The maximum pressure or probable water column separation in a fluid system may also cause damage to the system (Fawzy 2011).

This thesis concerns the investigation of problems resulting from unsteady flow in pipelines systems (high pressures - low pressures - vibration) to improve the design of pipeline.

This work studies the transient state analysis for the pipeline and provides the necessary recommendations 
of the different protection devices (air vessel and surge tower).

Unsteady flow conditions studied in the present work may create by various cases of pump starting, pump normal stop or shut down of the main discharge valve in the different hydraulic systems. The system simulated for non- protected and protected cases to analyze the unsteady flow problems for pressures.

\section{The following items will be study:}

- Effect of pipe material

- $\quad$ Effect of pipe diameter

- Effect of air vessel volume

The above mentioned items are examined separatelyin the case of the operating condition (sudden pump power failure), the pump has been rundown and the unsteady pressure heads are determined. The study illustrates the effect of using the appropriate control devices to control the unsteady flow problems.

Through this work, the parametric study was applied using Water Hammer Software Wanda V3.30. Wanda is considered a powerful program to study water hammer. This program developed and has validated against many experimental measurements (WL | Delft Hydraulics 2006). The program is available at the Hydraulics Research Institute (HRI), National Water Research Center, Egypt

\section{Fluid Specifications:}

1. The density is assumed to be constant (incompressible fluid).

2. Flow conditions are constant (discharge $=7.50$ $\left.\mathrm{m}^{3} / \mathrm{s}\right)$.

3. The kinematic viscosity $=0.1000 \mathrm{E}-05 \mathrm{~m}^{2} / \mathrm{s}$.

4. The bulk modulus $=0.2100 \mathrm{E}+10 \mathrm{~N} / \mathrm{m}^{2}$.

Time Parameter:

1. The time step $=0.06 \mathrm{sec}$.

2. The simulation end time $=800.0 \mathrm{sec}$.

Physical Constants:

1. The gravitational acceleration $=9.810 \mathrm{~m} / \mathrm{s}^{2}$.

2. The atmospheric pressure $=0.1014 \mathrm{E}+$

\section{2- System Configuration:}

Pumping station at elevation (9.00) consist of five parallel pumps are to be used to pump $7.50 \mathrm{~m}^{3} / \mathrm{sec}$ from elevation (8.80) at suction level to elevation (26.50) at delivery side before the open channel. The pumping station followed by a $1500 \mathrm{~mm}$ diameter delivery water to open channel at the end of pipeline. The pump discharge lines are check-valve and manifold into two Glass Reinforced Plastic pipeline $1500 \mathrm{~mm}$ in diameter. The pipe line extends from the pump station at elevation (9.00) for a distance of $8218 \mathrm{~m}$ at elevation (25.00) 1. Delivery water to open channel at the end of pipeline [Figures (1)].

\section{3- MODEL CALIBRATION}

In order to be confident with the model results, the model should be calibrated in order to tune the internal parameters in the model to force it to reproduce the required output to the case under consideration. To achieve the model calibration the value of surface roughness height of the pipe line was modified until reaching the measured value of discharge $\left(7.50 \mathrm{~m}^{3} / \mathrm{s}\right)$. The objective of the steady state analysis is to calibrate the model, to make sure that the model is well built, the model results are acceptable and to obtain the operating phases change of pumps at the different cases of operation. This was achieved by establishing a math point between the system curve and the pumps curve that was calculated by estimating the system static head and friction head.

\section{4- Model Scenarios:}

As mentioned before, four different scenarios for the transient pipelines were studied, included case of unsteady flow un protected, case of unsteady flow protected with air vessel, case of unsteady flow protected with air vessel and surge tower and case of unsteady flow protected with air vessel, case of unsteady flow protected with surge tower only. The results of each scenario are presented in the following.

\section{1- System without Protection:}

Five pumps are working together and fail suddenly, check valve closes upon power failure. The following events take place: the flow rapidly dimensioned to zero and then reverses; negative pressure waves are propagated downstream from the pump and positive pressure waves are propagated upstream through the suction pipe. The pump rapidly loses its forward rotation and reverses shortly after reversal of flow. As the pump increases in speed in the reverse direction, it causes greater resistance to flow which high pressure in the discharge line. When the load on the pumping system is primarily due to fluid fraction, as in the case of long discharge line, vapor pressure and column separation may occurs in the discharge line due to negative pressures. 
Column separation often occurs after pump power failure at the high point of pipeline.

The drop in pressure can also cause air to effervesce or emerge from solution and collect on the soffit or crown of the pipe. Bubbles may subsequently travel up the pipe and cause shock waves, especially on compression, when the water columns oscillate on each side of the air pocket, or when it escapes from air valves or joints (Stephenson 1997).

Figures (2) through (7) show that column separation and failure of pipeline started the maximum and minimum pressure envelope along the pipeline is 4.4 bar and -0.9969 bar at location from 1300 to $1400 \mathrm{~m}$. This means a column separation might occur in this place and it is the same place where the pipe damaged in the nature. The maximum cavitation volume is 0.001081 at the location $4300 \mathrm{~m}$. The previous values are unsafe and excess than the allowable (The working pressure of pipeline in the study case is 6 bars and 0.03 bar), so pipe system can be damaged by water hammer phenomena, the protection is a must.

\section{2- System with Protections:}

\subsection{1- Protected case (1) using air vessel:}

Air vessels offer an effective means of reducing water hammer overpressures and negative pressures due to pump trip in pipelines. A solution to this negative surge situation is to install an air vessel on the main header to protect the system see Figures (8) and (9). The purpose of this device is to limit the pressure drop and to avoid the possible occurrence of column separation in the pump during running condition and provide uniform flow of discharge during operation. In this case, it make the computations using the present hydraulic model to obtain the results when using air vessel with different capacities in order to search for an optimum solution to reduce the water hammer pressures and to prevent column separation. Figure (8) shows the schematic of air vessel (Watters 1984). Air vessel is supplied with air compressor to supply the air vessel with required compressed air.

Using the proposed air vessel as a protection device proved to be effective. Figures (10) through (12) show the curves for the protected system case (1), the maximum pressure in each pipeline changed and reached to 4.37 bars less than the working pressure (6 bars), the negative pressures in pipeline are reached ($0.02630 \mathrm{bars})$ which higher than the allowable $(-0.03$ bars).The cavitation volume equal zero at all pipeline location.

\subsection{2- Protected case (2) using air vessel and two surge towers:}

Surge tower is commonly used with air vessel to protect pipeline systems against column separation problems. The purpose of the surge tower is to mitigate pressure variations due to rapid changes in velocity of water.

When the load decreases, the water moves backwards and gets stored in it. When the load increases, additional supply of water will be provided by it. In this case we well use two surge towers with constant area equal $7.065 \mathrm{~m}^{2}$ and variable initial height of water surface (Figures (14) and (15).

Using the proposed surge towers with air vessel as a protection device proved to be not effective in this case because of the shape of this profile (the highest point of the pipe line is in the end of the pipe line so the delivery tank work as surge tower) but it can be effective in other cases.

\subsection{3- Protected case (3) using surge towers only:}

In this case two surge towers will be used with constant area equal $12.56 \mathrm{~m}^{2}$ and variable initial height of water surface as shown in Figure (20).

Figures (21) through (24) show the curves for the protected system case (3), the maximum pressure in each pipeline changed and reached to 2.103 bars less than the working pressure (6 bars), the negative pressures in pipeline are reached 0.1471 bars which higher than the allowable (-0.03 bars). The cavitation volume equal zero at all pipeline location.

Comparison of results for non-protected case and for protected cases is presented in Table (1).

\section{3- System Geometrical Design Changes:}

The transient performance of a piping system may be improved, in general, by changing the geometrical design. This design change may be particularly effective in suction lines, since it greatly decreases the possibility of cavitation.

\subsection{1- Effect of Pipe Diameter:}

In this case, the pervious hydraulic model is used to study the effect of pipe diameter to protect the pipe line against column separation problem. The main case diameter is $1500 \mathrm{~mm}$. The computations are made for another two values to get the results for the cases when the pipe diameter equals $1200 \mathrm{~mm}$ and $1800 \mathrm{~mm}$.

Comparison of results of protected cases are shown in Table (2) and comparison of the data of the air vessel are shown in Table (3). 
Increases the diameter of the pipeline reduce the surge pressures. This occurs as the velocity is reduced. The downside is the increased cost of the pipe.

Decreases the diameter of the pipeline increase the surge pressures. This occurs as the velocity is increased. The downside is the decreased cost of the pipe.

Increase the diameter of the pipeline, the immediate effect is to reduce the surge pressures. Since head change is directly proportional to velocity change, this occurs as the velocity is reduced. The downside is that the increased pipeline size reduces the friction. So the damping of any pressure fluctuations is reduced and the transient may also considerably longer. This adds to the loading of components in the system. The increase of pipe diameter also increase the price of the pipes but it decrease the price of the air vessels since the total volume required to protect the pipe line system against water hammer problem is decreased and the negative pressure of the pipe line is decreased.

\subsection{2- Effect of Pipe Material}

In this case, the pervious hydraulic model is used to study the effect of pipe material, to protect the pipe line against column separation problem. The computations are made for another type of pipe material, from GRP to steel and concrete.

Comparison of results for protected cases using air vessel is presented in Table (4) and comparison of the data of the air vessel are shown in Table (5).

Change of pipe material from GRP to steel or concrete leads to reduce the value of minimum pressure. Changing from GRP to concrete reduce the total volume of protection (number of used air vessels) as the wall roughness height of concrete $(0.3 \mathrm{~mm})$ is higher than it of GRP $(0.04 \mathrm{~mm})$ and this make the value of discharge changed but to protect the steel pipe line system it will be used the same volume of protection because the wall roughness height of steel is $(0.06 \mathrm{~mm})$ very near of the GRP .

\subsection{3- Effect of air vessel volume:}

In this case, the pervious hydraulic model is used to study the effect of air vessel volume to protect the pipe line against column separation problem.

The computations are made for another value to get the results for the cases when the air vessel number equal 10 when the air vessel volume equal $84.813 \mathrm{~m}^{3}$ and another case when the air vessel number equal 14 when the air vessel volume equal $60.54 \mathrm{~m}^{3}$.

Comparison of results for protected cases using different volumes of air vessel is presented in Table (6) and the data of air vessels are presented in Table (7).
The total volume required to protect the pipe line system is fixed but we can change number and volume of used air vessels as which volume is available. From using different volumes of air vessel it was found that as the air vessel volume is reduced the number of used air vessels is increased and the negative pressure of the pipe line is not affected

\section{5- CONCLUSIONS}

This research attempts to determine the pressure heads resulting from the transient flow in pipeline systems caused by the failure of pumps. This pipe line system is already exist in EL- Salheya city at Ismalia Cairo road. From such analysis, the following conclusions were made:

- Column separation often occurs after pump failure at the high point of pipeline.

- Using air vessel protects effectively the pipeline against column separation.

- Air vessel with surge towers might be used to protect the pipeline against column separation and decrease the initial air vessel volume and might not affect the air vessel volume.

- Using surge tower only cannot be applied to protect the pipeline against column separation because it is too high.

- Increasing the diameter of the pipeline reduces the surge pressures. This occurs as the velocity is reduced. This increases the cost of the pipe and decreases the total volume required to protect the system.

- Using of concrete pipes instead of GRP pipes will reduce the minimum pressure and will also reduce the total volume of protection.

- Using of steel pipes instead of GRP pipes might reduce the minimum pressure but it would not affect the total volume of protection.

- As the air vessel volume is reduced, the number of used air vessels is increased and the negative pressure of the pipe line not affected.

\section{RECOMMENDATIONS}

It is not easy to generalize the results of the present analyses as the analysis must undertake a number of laborious reanalyzes before achieving a satisfactory design. Therefore, the present research indicated that the following recommendations might be taken into consideration for the future studies:

- Other factors should be taken into considerations (i.e. there are other factors affecting the surge pressure head resulting 
from transient flow such that the type of flowing liquid, and the effect of changing the polar moment of inertia).

- An extensive experimental investigation of the transient flow in pipeline is required to compare the results with the results of the mathematical model.

\section{ACKNOWLEDGMENTS}

This work is part of MSC. Thesis of the first author and supervised by the other authors. The authors are gratefully to the Hydraulics Research Institute, HRI; National Water Research Center, Egypt.

\section{REFRENCES}

- Allievi, L., 1925. Theory of water Hammer, (Translated by E.E. Halmos), Riccardo GaronRormme.

- Angus, Robert, W., 1935. Simple Graphical Solution for Pressure Rise in pipes and Pump Discharge Lines, J. Eng. Inst., Canada, pp: 7281.
- Bergoron, L., 1961. Water Hammer in Hydraulics and Wave Surges in Electricity, (Translated under the Sponsorship of the ASME), John Wiley \& Sons, Inc., New York.

- Eman Fawzi, Improving Design of Irrigation Pipeline Networks, Egypt 2011.

- Douglas, J.F., et al., 1995. Fluid Mechanics, ELBS, Third Edition, Longman Singapore Publishers.

- Douglas, S., 1974. Elements of Hydraulic Engineering, Van Nostrand Co., Inc., New York, N.Y.

- Stephenson, D., 1997. Effects of Air Valves and Pipework on Water Hammer Resurges, J. Transp. Eng, 123(2):101-106

- Streeter, V.L. and E.B. Wylie, 1967. "Hydraulic Transient", McGraw-Hill Book Co. (Now Sold by University Microfilms, Ann Arbor, Michigan).

- User Manual WANDA3.03- User Interface, January,2000.

- WANDA development team," WANDA Validation", Version 3.5x, Prepared for: WL | Delft Hydraulics Report September, 2006. 


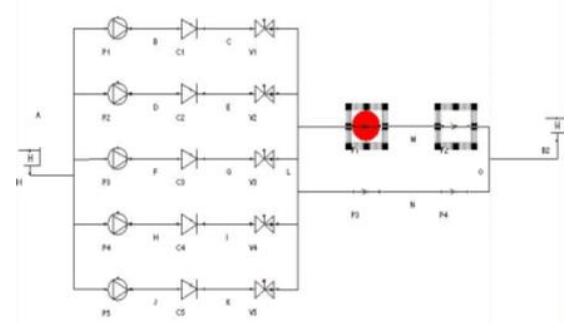

Figure (1): Schematic illustration of the hydraulic system

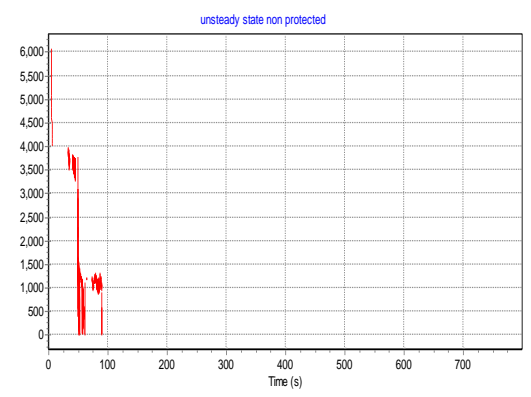

- Discharge PUMPPI

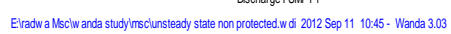

Figure (2): Discharge - time history

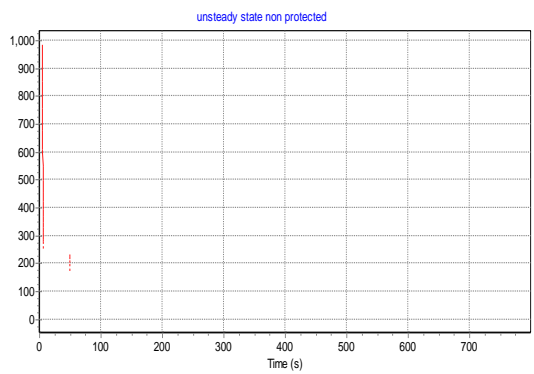

Purp speed Pupp P1

Eivadwa Nsciw anda studyimsciunsteady state non protected.w.wi 2012 Sep 11 10:45 - Wanda 3.03

Figure (3): Pump speed - time history

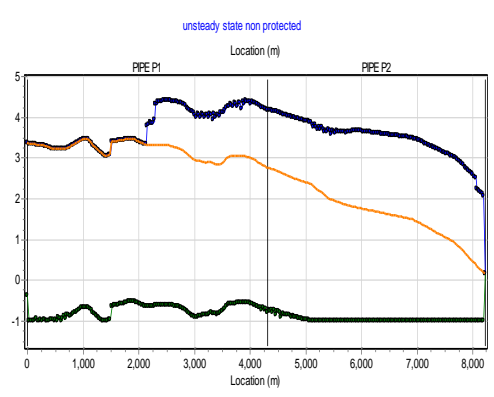

- Pressure min - Pressure max - Pressure 0.000

Eiradwa Msciwanda studymsel

Fig. (4): Pressure envelope and pressure profiles at various time along the pipelines. 


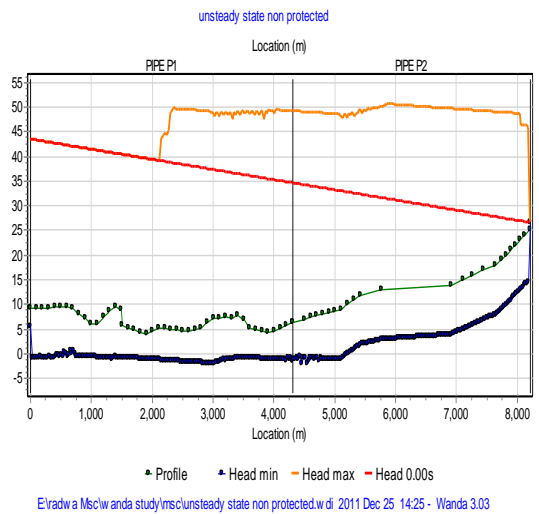

Fig. (5): Head envelope and head profiles at various time along the pipelines.

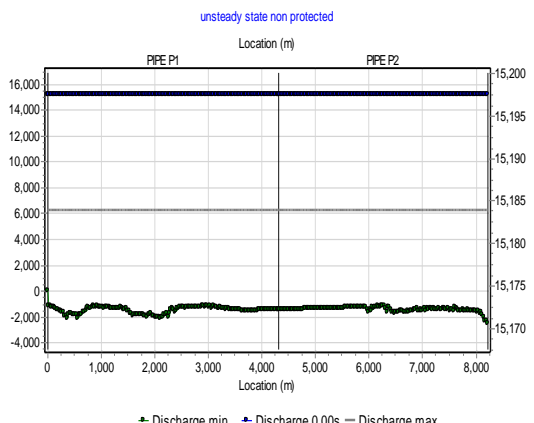

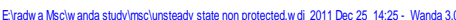

Fig. (6): Discharge envelope and discharge profiles at various time along the pipelines.

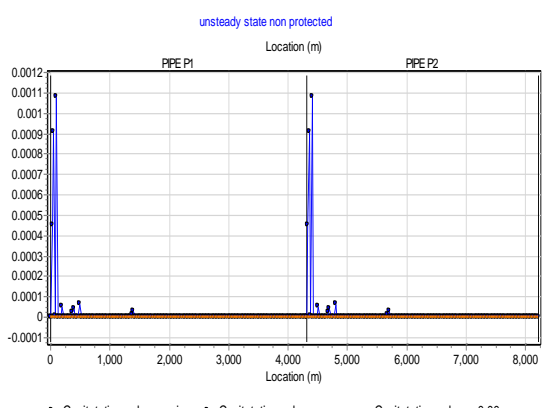

Figure (7): Cavitation volume - location

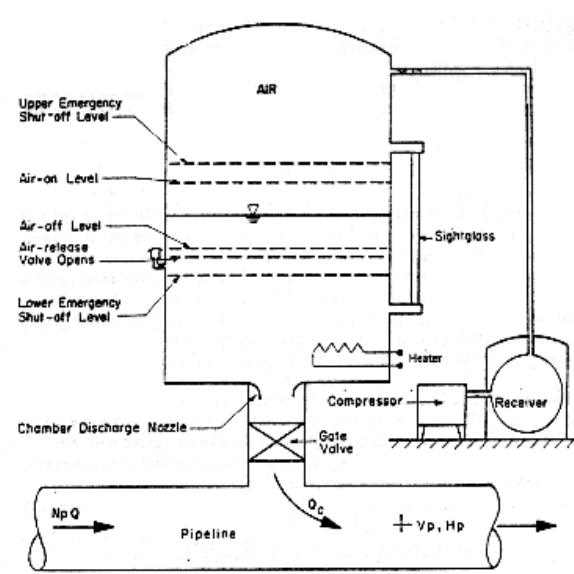

Figure (8): Schematic diagram of an air chamber and its appurtenances (Watters [1984]) 


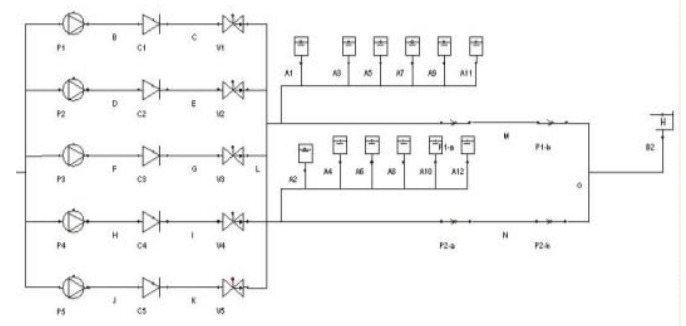

Figure (9): Schematic diagram of unsteady state protected with air vessel

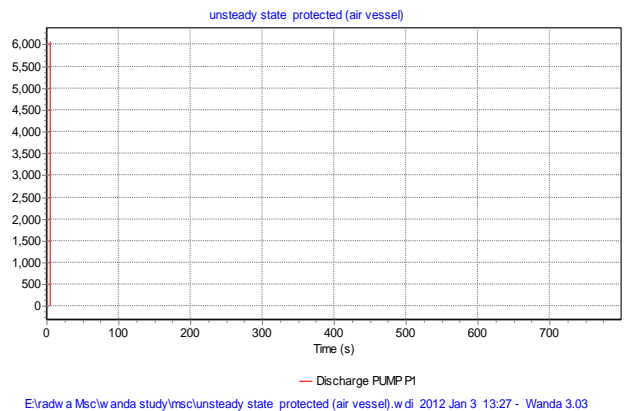

Figure (10): Discharge - time history

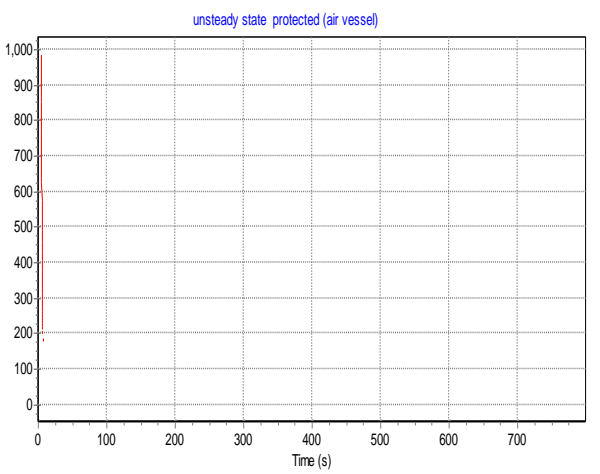

- Pump speed PUMPP1

Eirradw a Nsciw anda study msciunsteady state protected (arr vessel).wdi 2012 Jan 3 13:27- Wanda 3.03

Figure (11): Pump speed - time history

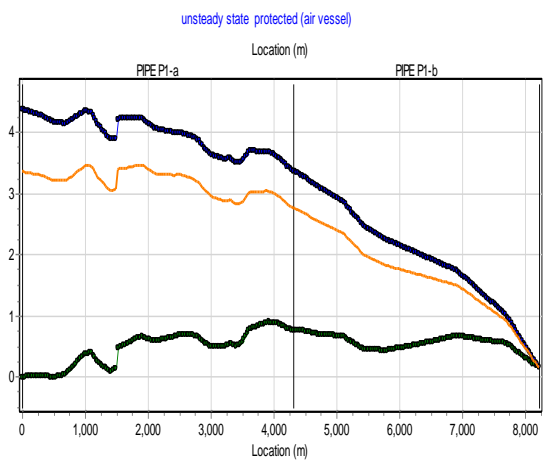

$\rightarrow$ Pressure min $*$ Pressure $\max -$ Pressure 0.00 s

Citradualunsteady state protected (ari vessel).Wdi 2012 Jan 313.27 - Wanda 3.03

Figure (12): Pressure profiles at various times along pipelines. 


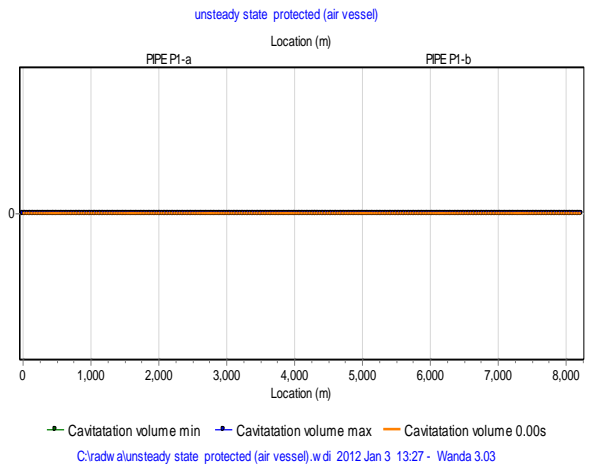

Figure (13): Cavitation volume - location

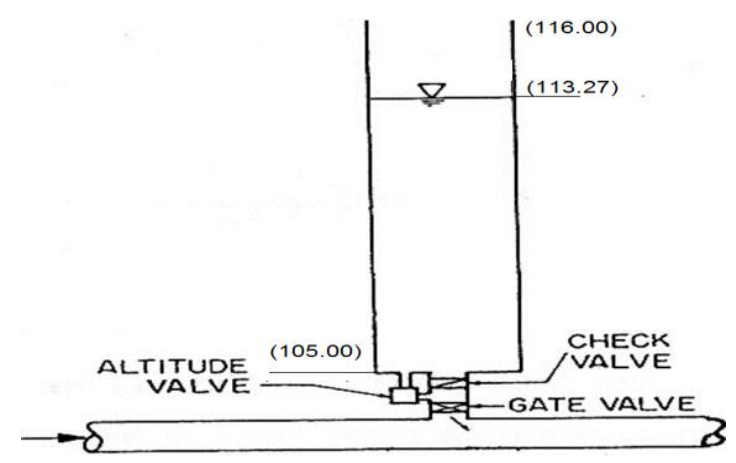

Figure (14): A Schematic of surge tank designs (Douglas [1974], Watters [1984])

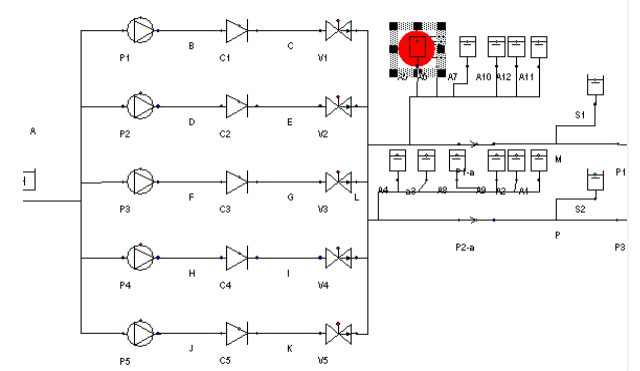

Figure (15): Schematic illustrates the installation of air vessel and surge towers

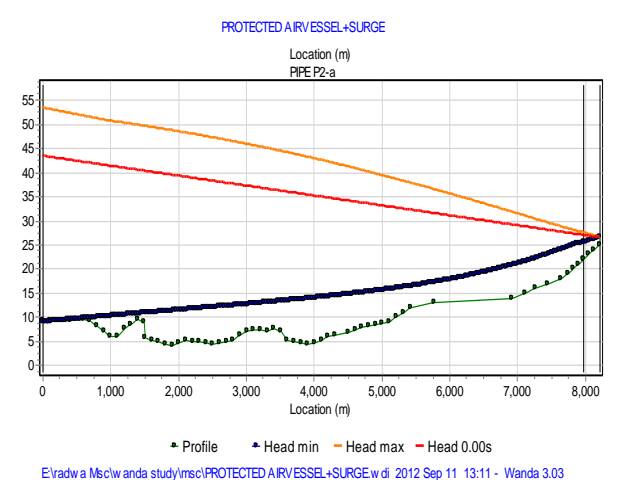

Figure (16): Head envelope 


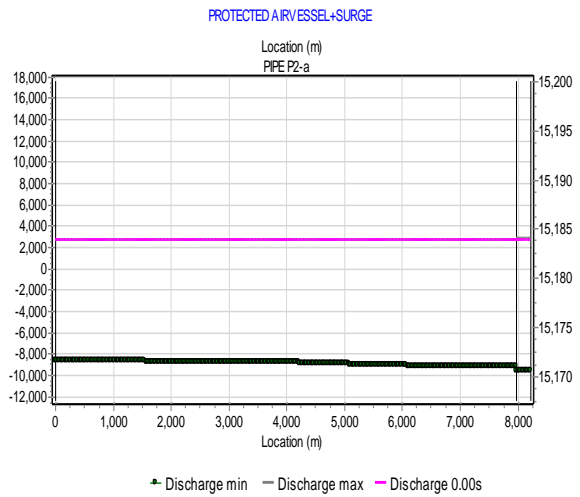
Eivadwa NSciw anda study'msc PrOTECTED ARVESSE+SURGEw wi 2012 Sep 11 13:11 - Wanda 3.03

Figure (17): Discharge envelope

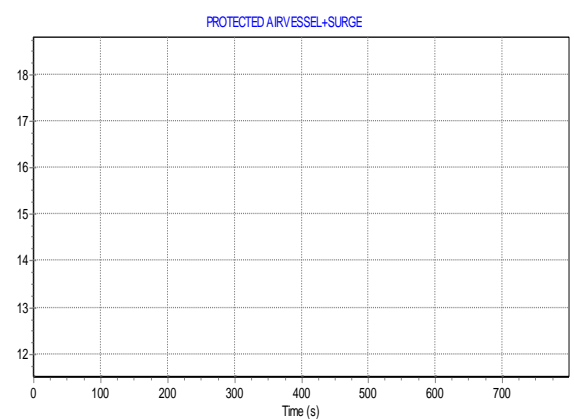

- Fuid level AIRVnn A5

Eiradwa Msciwanda study

Figure (18): Fluid level - time history

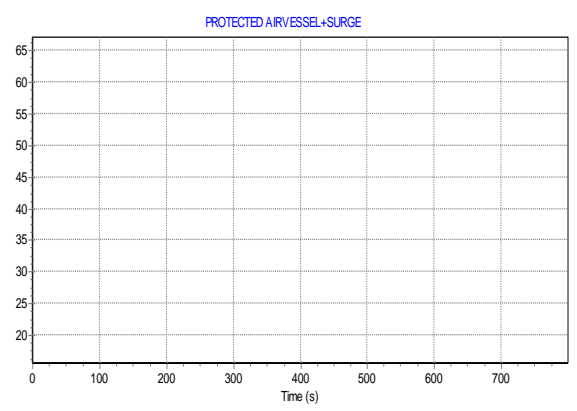

- Air voume ARVun As

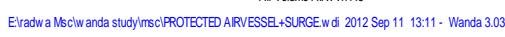

Figure (19): Air volume -time history

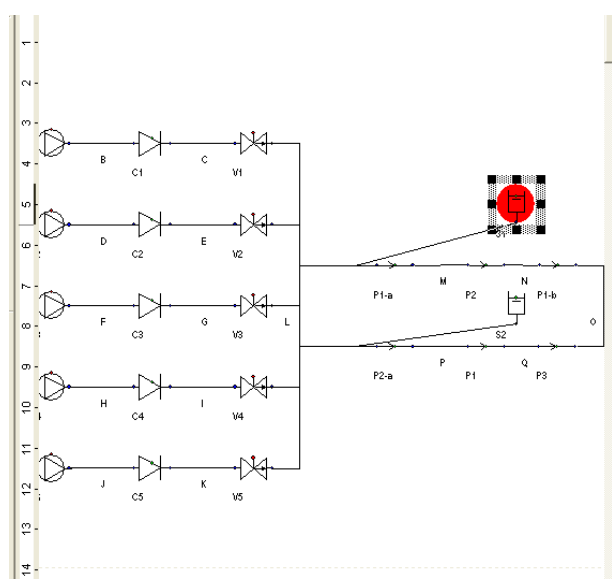

Figure (20): Schematic illustrates the installation of surge towers only 


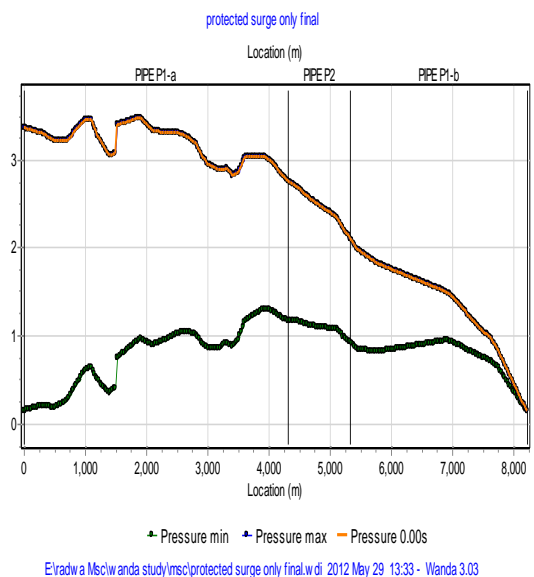

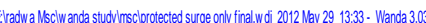

Figure (21): Pressure envelope

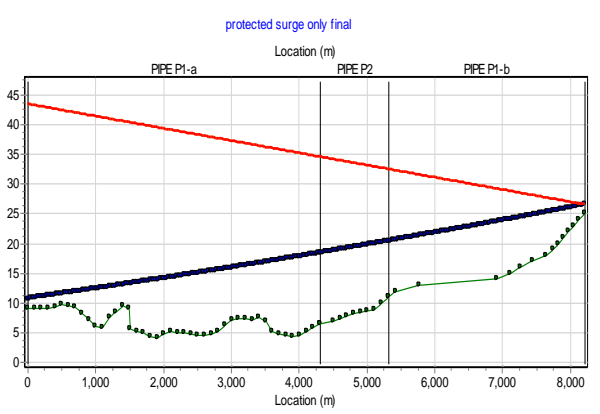

- Profile - Head min - Head max - Head 0.00s

Eivadwa Msciw anda study'msciprotected surge only final.woil 2012 May 29 13:33. Wanda 3.03

Figure (22): Head envelope

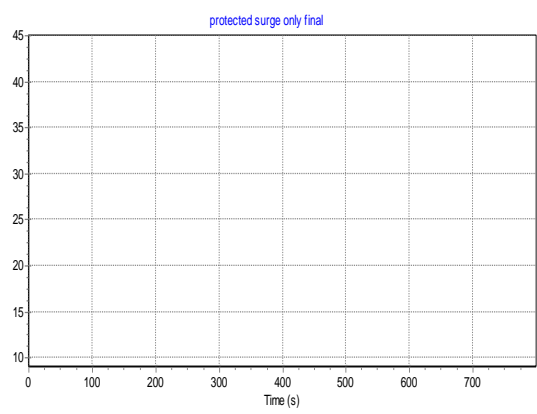

- Fuid level SURGTW S1

Eiradiwa Msciwanda study imscipolected surge ony final.woi 2012 Sep 11 10:12. Wanda 3.03

Figure (23): Fluid level - time history

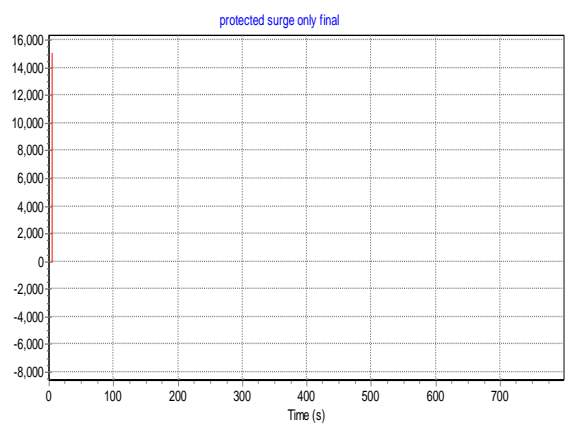

- Discharge SURGTW S1

Eiradwa Nsciwanda study imsciprotected surge only finalw wi 2012 Sep 11 10:12. Wanda 3.03

Figure (24): Discharge wave propagation 
Table 1: Comparison of results

\begin{tabular}{|c|c|c|c|c|c|c|}
\hline \multicolumn{2}{|c|}{ Cases steady } & $\begin{array}{c}\text { Steady } \\
\text { state }\end{array}$ & $\begin{array}{c}\text { Non - } \\
\text { protected } \\
\text { case }\end{array}$ & $\begin{array}{c}\text { Protected case } \\
(1)\end{array}$ & $\begin{array}{c}\text { Protected case } \\
(2)\end{array}$ & $\begin{array}{c}\text { Protected case } \\
(3)\end{array}$ \\
\hline \multirow{2}{*}{ Pressure bar } & Minimum & 0.00 & -0.9969 & -0.0263 & -0.0211 & 0.1471 \\
\cline { 2 - 7 } & Maximum & 3.426 & 4.4 & 4.37 & 4.369 & 2.103 \\
\hline \multirow{2}{*}{$\begin{array}{l}\text { Discharge } \\
\mathrm{m}^{3} / \mathrm{h}\end{array}$} & Minimum & 15.18 & -2128 & -8885 & -9227 & -7740 \\
\cline { 2 - 7 } & Maximum & 15.18 & 15180 & 15180 & 15180 & 15180 \\
\hline \multirow{2}{*}{ Head m } & Minimum & 26.5 & -1.997 & 8.991 & 8.984 & 20.40 \\
\cline { 2 - 7 } & Maximum & 43.38 & 49.56 & 53.75 & 53.37 & 32.43 \\
\hline \multicolumn{2}{|c|}{ Cavitation volume } & 0.00 & 0.00108 & 0.00 & 0.00 & 0.00 \\
\hline
\end{tabular}

Table (2): Comparison of results of protected cases

\begin{tabular}{|c|c|c|c|c|}
\hline \multicolumn{2}{|c|}{ Pipe material } & \multicolumn{3}{|c|}{ GRP } \\
\hline \multicolumn{2}{|c|}{ Wall thickness $\mathrm{mm}$} & 35 & 30 & 45 \\
\hline \multicolumn{2}{|c|}{ pipe diameter $\mathbf{m m}$} & 1200 & 1500 & 1800 \\
\hline \multirow{2}{*}{ 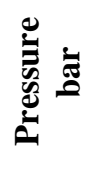 } & Minimum & 0.147 & -0.026 & -0.025 \\
\hline & Maximum & 4.383 & 4.37 & 5.391 \\
\hline \multirow{2}{*}{ 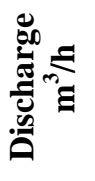 } & Minimum & -4813 & -8885 & -11950 \\
\hline & Maximum & 15180 & 15180 & 15180 \\
\hline \multirow{2}{*}{$\underset{\mathbb{E}}{\mathbb{Z}} \Xi$} & Minimum & 17.80 & 8.991 & 8.941 \\
\hline & Maximum & 51.13 & 53.75 & 64.16 \\
\hline \multicolumn{2}{|c|}{ Cavitation volume } & 0.00 & 0.00 & 0.00 \\
\hline \multicolumn{2}{|c|}{ Chamber area $\mathbf{m}^{2}$} & 7.065 & 7.065 & 7.065 \\
\hline
\end{tabular}


Fathy M. Radwa, El Sayed T., Hamdy W., and Ramdan K" Computer analysis of the different

Table (3): Comparison of the data of the air vessel

\begin{tabular}{|l|c|c|c|}
\hline Pipe diameter mm & $\mathbf{1 2 0 0}$ & $\mathbf{1 5 0 0}$ & $\mathbf{1 8 0 0}$ \\
\hline Top level m & 21 & 21 & 21 \\
\hline Bottom level m & 11 & 11 & 11 \\
\hline Initial fluid level m & 18 & 7.065 & 7.065 \\
\hline Chamber area $\mathbf{~ m}^{\mathbf{2}}$ & 7.065 & 12 & 12 \\
\hline Number of air vessel & 14 & 847.8 & 847.8 \\
\hline Total volume $\mathbf{~ m}^{\mathbf{3}}$ & 989.1 & 18 & 12 \\
\hline
\end{tabular}

Table (4): Comparison of results of protected cases

\begin{tabular}{|c|c|c|c|c|}
\hline \multicolumn{2}{|c|}{ Pipe diameter $\mathbf{m m}$} & \multicolumn{3}{|c|}{1500} \\
\hline \multicolumn{2}{|c|}{ Wall thickness mm } & 30 & 10 & 150 \\
\hline \multicolumn{2}{|c|}{ Pipe material } & GRP & Steel & Concrete \\
\hline \multirow{2}{*}{ 莺 } & Minimum & -0.026 & 0.0653 & 0.0252 \\
\hline & Maximum & 4.37 & 4.388 & 4.337 \\
\hline \multirow{2}{*}{ 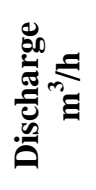 } & Minimum & -8885 & -8154 & -7621 \\
\hline & Maximum & 15180 & 13500 & 13500 \\
\hline \multirow{2}{*}{$\underset{\mathbb{E}}{\mathbb{Z}} \Xi$} & Minimum & 8.991 & 9.86 & 9.45 \\
\hline & Maximum & 53.75 & 53.93 & 52.93 \\
\hline \multicolumn{2}{|c|}{ Cavitation volume } & 0.00 & 0.00 & 0.00 \\
\hline \multicolumn{2}{|c|}{ Chamber area $\mathbf{m}^{2}$} & 7.065 & 7.065 & 7.065 \\
\hline
\end{tabular}


Table (5): Comparison of the data of the air vessel

\begin{tabular}{|l|c|c|c|}
\hline \multicolumn{1}{|c|}{ Pipe material } & GRP & Steel & Concrete \\
\hline Top level m & 21 & 21 & 21 \\
\hline Bottom level m & 11 & 11 & 11 \\
\hline Initial fluid level m & 18 & 18 & 18 \\
\hline Chamber area $\mathbf{~ m}^{\mathbf{2}}$ & 7.065 & 7.065 & 7.065 \\
\hline Number of air vessel & 12 & 12 & 706.5 \\
\hline Total volume $\mathbf{~ m}^{\mathbf{3}}$ & 847.8 & 847.8 & 10 \\
\hline
\end{tabular}

Table (6): Comparison of results of protected cases

\begin{tabular}{|c|c|c|c|c|}
\hline \multicolumn{2}{|c|}{ Total volume of air vessels } & \multicolumn{3}{|c|}{847.8} \\
\hline \multicolumn{2}{|c|}{ Volume of one air vessel } & 70.65 & 84.78 & 60.557 \\
\hline \multicolumn{2}{|c|}{ Number of air vessel } & 12 & 10 & 14 \\
\hline \multirow{2}{*}{ 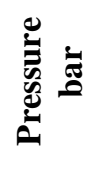 } & Minimum & -0.026 & -0.026 & -0.026 \\
\hline & Maximum & 4.37 & 4.37 & 4.37 \\
\hline \multirow{2}{*}{ 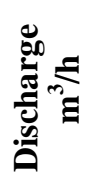 } & Minimum & -9108 & -9108 & -9108 \\
\hline & Maximum & 15180 & 15180 & 15180 \\
\hline \multirow{2}{*}{ 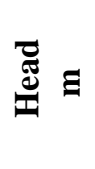 } & Minimum & 8.991 & 8.991 & 8.991 \\
\hline & Maximum & 53.75 & 53.75 & 53.75 \\
\hline \multicolumn{2}{|c|}{ Cavitation volume } & 0.00 & 0.00 & 0.00 \\
\hline \multicolumn{2}{|c|}{ Chamber area $\mathrm{m}^{2}$} & 7.065 & 8.478 & 8.478 \\
\hline
\end{tabular}


Table (7): Comparison of the data of the air vessel

\begin{tabular}{|l|c|c|c|}
\hline Volume of one air vessel & 70.65 & 84.813 & 60.557 \\
\hline Top level m & 21 & 21 & 21 \\
\hline Bottom level m & 11 & 11 & 11 \\
\hline Initial fluid level m & 18 & 18 & 6.065 \\
\hline Chamber area $\mathbf{~ m}^{\mathbf{2}}$ & 7.065 & 8.478 & 14 \\
\hline Number of air vessel & 12 & 10 & 847.8 \\
\hline Total volume $\mathbf{~ m}^{\mathbf{3}}$ & 847.8 & 847.8 & 18 \\
\hline
\end{tabular}

